\title{
Hepatectomía derecha totalmente laparoscópica para trasplante hepático con donante vivo adulto-adulto. Técnica quirúrgica y experiencia inicial en Chile
}

\author{
Brenda A. Gamez del Mauro ${ }^{1}$, Erwin Buckel G. ${ }^{2}$, Felipe Puelma C. ${ }^{2,3}$, \\ Erwin Buckel Sc. ${ }^{2,4}$, Cristian Astorga L. ${ }^{2}$ y Nicolás Jarufe C. ${ }^{2}$
}

'Fellow de Investigación en Cirugía Hepatobiliar y Trasplantes Universidad de Chile - Clínica Las Condes. Santiago, Chile. 2Departamento Cirugía Clínica Las Condes. Santiago, Chile. ${ }^{3}$ Hospital del Salvador. Santiago, Chile. ${ }^{4}$ Hospital Sotero del Río. Santiago, Chile.

Recepción 2021-03-04 aceptado 2021-04-08

Correspondencia a: Dr. Nicolás Jarufe C. njarufe@clinicalascondes.cl
Pure laparoscopic right hepatectomy for adult-to-adult living donor liver transplantation: Surgical technique and initial experience in Chile

Living donor liver transplantation is a complex and challenging procedure. The surgeon needs to guarantee maximum safety for the donor, as well as the best quality of the graft for the recipient. For this reason, the implementation of mini-invasive surgery has been slow in this area. However, in the last 10 years, due to the advances in laparoscopic liver surgery, the interest of some highly specialized groups has increased in incorporating mini-invasive surgery into donor surgery, mainly in pediatric living donor liver transplantation. The favorable results obtained in this field, have even led to turn this procedure, into the technique of choice for pediatric living donor liver transplantation. Nevertheless, this procedure is even more challenging for adult-to-adult living donor transplantation. To meet the volumetric criteria of an adult, a complete hepatectomy of right or left lobe is mostly required. This surgery is of greater complexity and risk for the donor, so its indication by minimally invasive approach is limited to high-volume centers with preparation, both in laparoscopy and liver transplants. In this report we seek to present our surgical technique and initial experience with the first pure laparoscopic right hepatectomy for adult-to-adult living donor liver transplantation carried out in Chile.

Keywords: liver transplantation; living donor; right hepatectomy; laparoscopic.

\section{Resumen}

El trasplante hepático con donante vivo (THDV) es un procedimiento complejo y desafiante para el cirujano, ya que exige garantizar tanto la máxima seguridad para el donante, así como también, la mejor calidad del injerto para el receptor. Debido a lo anterior, la implementación de la cirugía miniinvasiva ha sido lenta en esta área. Sin embargo, en los últimos 10 años, gracias a los avances que ha experimentado la cirugía hepática laparoscópica, ha aumentado el interés de algunos grupos altamente especializados por incorporar la cirugía mini-invasiva a la cirugía del donante, principalmente en trasplante hepático donante vivo adulto-pediátrico (THDVA-P). Los favorables resultados obtenidos en esta área incluso han llevado a los expertos en el tema, a categorizar el abordaje laparoscópico para la cirugía del donante como el procedimiento estándar en THDVA-P. Contrario a lo anterior, la implementación de la laparoscopía para trasplante hepático donante vivo adulto-adulto (THDVA-A), es más compleja y requiere en su mayoría, una hepatectomía de lóbulo derecho o izquierdo para cumplir con las necesidades volumétricas del receptor. Esta cirugía es de mayor dificultad y riesgo para el donante, por lo que su indicación por vía mini-invasiva está limitada a centros de alto volumen y preparación, tanto en laparoscopía, como en trasplante hepático. En este trabajo, se busca dar a conocer la técnica quirúrgica y nuestra experiencia inicial con la primera hepatectomía derecha totalmente laparoscópica (HDTL) para THDVA-A realizada en Chile.

Palabras clave: trasplante hepático; donante vivo; hepatectomía derecha; laparoscopía. 


\section{Introducción}

A pesar de un inicio relativamente lento, debido a su alta complejidad, la cirugía hepática laparoscópica es actualmente realizada en muchos centros experimentados alrededor del mundo ${ }^{1}$. Después del primer consenso internacional sobre cirugía hepática laparoscópica, este procedimiento se ha instaurado como seguro y eficaz, sobre todo para resecciones hepáticas menores ${ }^{2}$. Sin embargo, las resecciones hepáticas mayores aún constituyen una técnica en desarrollo. Las recomendaciones del Segundo Consenso Internacional sobre cirugía hepática laparoscópica de Morioka, Japón, en octubre de 2014, describen estos procedimientos aún en fase de aprendizaje ${ }^{3}$.

En relación con el trasplante hepático con donante vivo (THDV), la técnica completamente laparoscópica para la cirugía del donante en THDVA-P, ha conseguido instaurarse y validarse como el nuevo procedimiento estándar según el último consenso de expertos en $2015^{4}$. A la fecha, numerosos centros han publicado sus resultados al respecto, demostrando los beneficios de la técnica mini-invasiva para la cirugía del donante en comparación a la tradicional abierta $^{5}$. En nuestro país, debido a la baja tasa de donación cadavérica, también se ha desarrollado el THDV, y al igual que a nivel global, principalmente para receptor pediátrico. El primer caso en que la cirugía del donante se realizó de manera completamente laparoscópica para un receptor pediátrico, fue el año $2013^{6}$.

Contrario a lo anterior, el THDVA-A no ha evolucionado de igual manera. Son pocos los centros que realizan este procedimiento y aún más escasos los que describen la técnica de HDTL para la cirugía del donante. En este procedimiento, a diferencia del trasplante hepático para receptor pediátrico, el riesgo al cual se somete al donante es aún mayor. Un receptor adulto requiere un mayor volumen del injerto que uno pediátrico, esto implica realizar una hepatectomía de lóbulo completo derecho o izquierdo, un procedimiento mucho más desafiante y complejo técnicamente, que requiere avanzadas habilidades del equipo de cirujanos tanto en trasplante hepático, como en cirugía hepatobiliar mini-invasiva ${ }^{1}$.

A pesar de lo anterior, en los últimos dos años el THDVA-A se ha desarrollado exponencialmente en países asiáticos, donde por razones culturales la donación cavérica no es realizada de manera prioritaria. Y, aunque escasos, algunos centros han publicado estudios comparativos y prospectivos sobre THDVA-A donde la cirugía del donante es realizada mediante HDTL, comparándola con la técnica tradicional abierta ${ }^{7-11}$. Sus resultados han demostrado que, cuando se cuenta con la experiencia y tecnología adecuada, la HDTL para la cirugía del donante puede convertirse en una técnica factible y segura con todos los beneficios de la cirugía miniinvasiva. El objetivo del presente trabajo es exponer la técnica quirúrgica y experiencia inicial de nuestro centro respecto al THDVA-A, donde la cirugía del donante se realizó mediante una HDTL.

\section{Donante y receptor}

En septiembre de 2020 se ofreció el abordaje laparoscópico a una paciente mujer de 30 años, voluntaria para THDVA-A para su hermano con diagnóstico de colangitis esclerosante, secundaria a isquemia de vía biliar posparo cardio-circulatorio. El puntaje MELD Na+ $\mathrm{Nr}^{+}$praplante del receptor era de 11 puntos, MELD operacional de 20 puntos y un Child-Pugh A. El peso de la donante era de $80 \mathrm{~kg}$ y el del receptor de $64 \mathrm{~kg}$. El volumen hepático total de la paciente, calculado mediante evaluación volumétrica por tomografía computarizada de abdomen, era de $1.954 \mathrm{~mL}$ y el lóbulo derecho (segmentos $\mathrm{V}$, VI, VII y VIII) era de $924 \mathrm{~mL}$ sin la vena hepática media (VHM) (Figura 1A). El volumen hepático residual fue de $666 \mathrm{~mL}$, que equivalía al 41,8\% del volumen total del hígado de la donante (Figura 1B). El índice peso del injerto/peso del receptor fue de 1,45 (GW/RW ratio, en inglés). Las ramas afluentes de los segmentos V y VIII a la VHM eran $<5 \mathrm{~mm}$. La anatomía de la arteria hepática y vena porta eran normales. La vía biliar se estudió de manera independiente con colangiorresonancia, que demostró bifurcación intrahepática de los conductos biliares derecho anterior y posterior, sin otras variantes.

A manera de obtener una detallada planificación quirúrgica pretrasplante, se realizó, en conjunto con el Centro de Innovación en Salud de Clínica Las Condes, un modelo 3D del hígado de la donante. Mediante la tecnología de impresión 3D, el modelo se pudo imprimir y ser un apoyo a la planificación prequirúrgica (Figura 2).

Tanto donante como receptor dieron su consentimiento informado sobre el procedimiento, y se les explicaron los posibles riesgos y complicaciones. El equipo de trasplante afirmó que este procedimiento no se había realizado previamente en nuestro centro. La dirección médica de Clínica Las Condes, junto a un equipo multidisciplinario de tratantes dieron la autorización. El Comité de Ética de Clínica Las Condes dio autorización y constancia sobre la publicación de este trabajo. La donante firmó un consen- 


\section{CIRUGÍA AL díA}

Figura 1. A: TC de abdomen, volumetría lóbulo hepático derecho del donante. B: Porcentaje volumen residual del hígado donante.
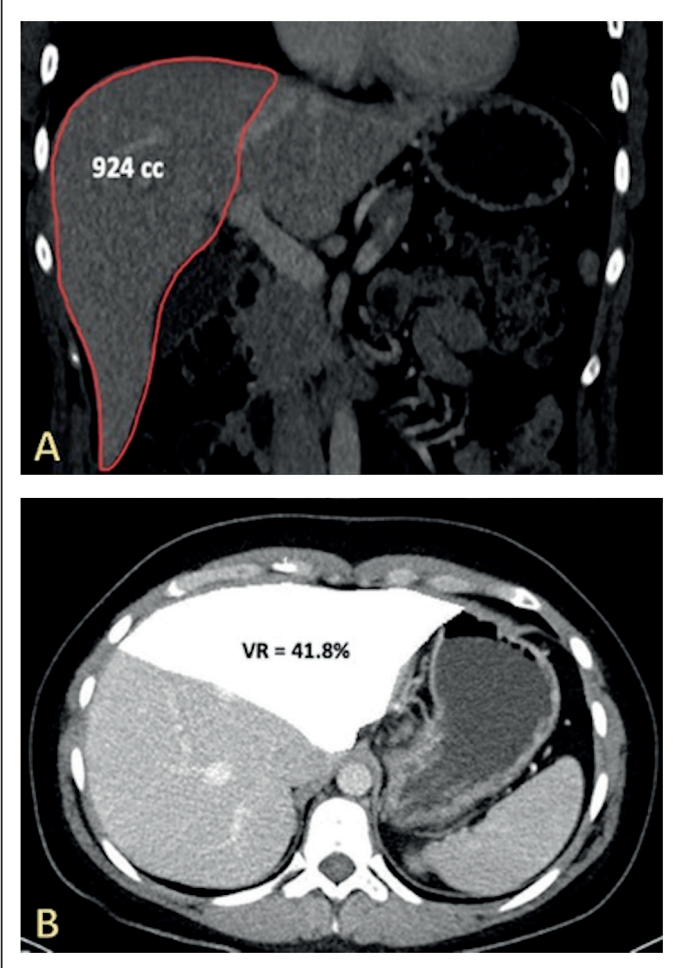

timiento informado institucional para la publicación de su caso en un trabajo con fines de investigación científica.

\section{Técnica quirúrgica}

El paciente es colocado en posición decúbito supino con elevación a $30^{\circ}$ del hombro derecho y Trendelenburg invertido. El cirujano se ubica en posición francesa, entre las piernas del paciente y el ayudante a la derecha de este. Trócares ubicados según Figura 3. Se ingresa a la cavidad peritoneal y se obtiene neumoperitoneo con $\mathrm{CO}_{2}$ y aguja de Veress. Se utilizó insuflación doble a $15 \mathrm{mmHg}$ de manera de mantener presiones estables durante todo el procedimiento y que no declinen en caso de sangrado y/o aspiración. Durante la transección del parénquima hepático, se elevaron las presiones de $\mathrm{CO}_{2}$ a $18 \mathrm{~mm}$ de $\mathrm{Hg}$. Se introduce la óptica de $30^{\circ}$ y se explora la cavidad abdominal. Se utilizaron como instrumentos de disección el dispositivo de energía Harmonic ${ }^{\circledR}$ HD 1000i y gancho. Para la oclusión de vasos sanguíneos de mayor calibre, se utilizaron clips poliméricos Hem-o-lok ${ }^{\circledR}$.

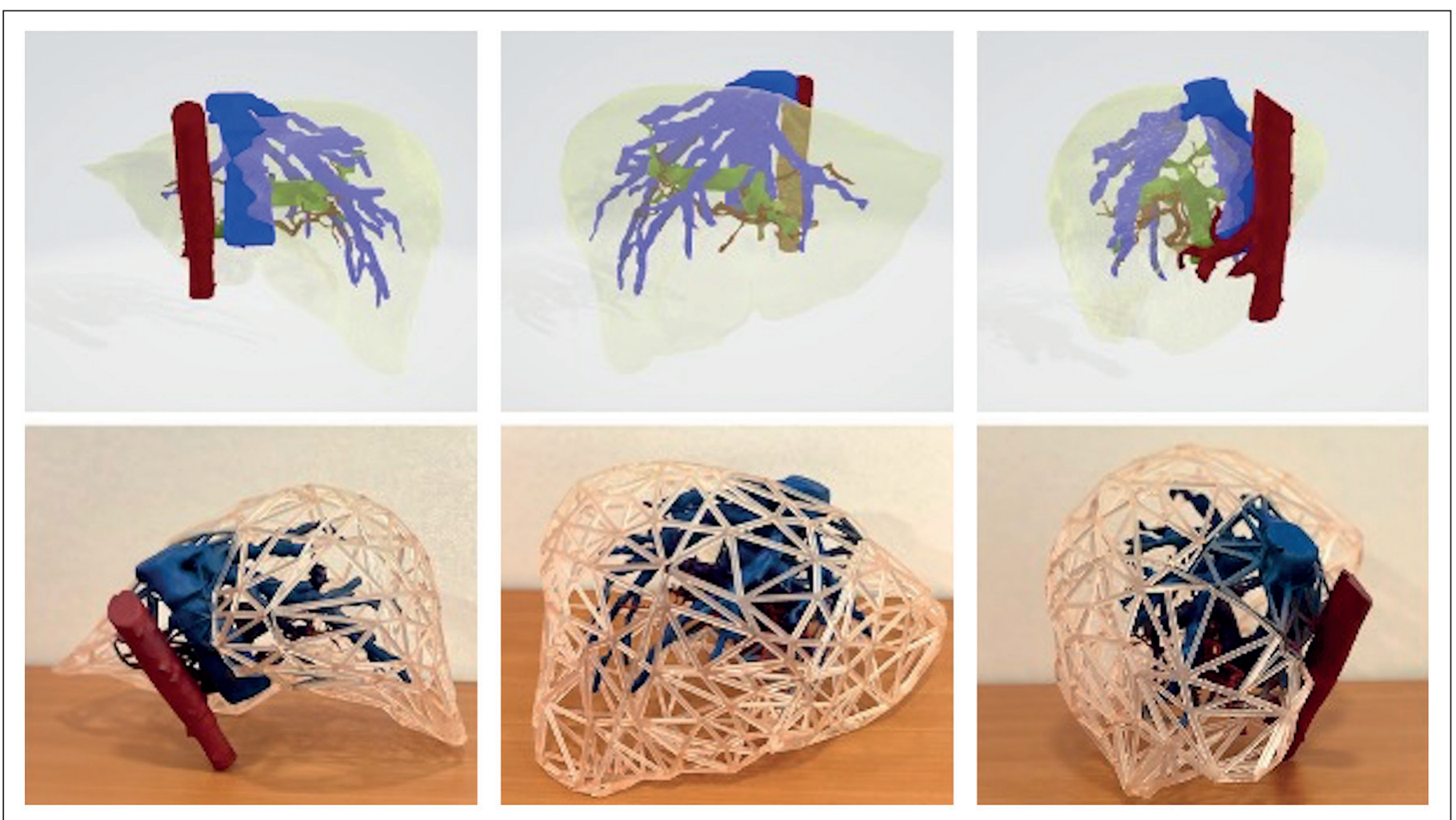

Figura 2. Modelo 3D hígado del donante. 
Se procede a la liberación del lóbulo hepático derecho utilizando el dispositivo de energía Harmonic $^{\circledR}$ HD 1000i. Se secciona el ligamento coronario, el triangular derecho (Figura 4A) y el falciforme, liberando las salidas de las venas hepáticas. Luego se realizó la disección de la vena cava retrohepática ligando y seccionando ramas del caudado hasta identificar el ligamento hepato-cavo que también se seccionó (Figura 4B). De esta manera se obtiene una mejor visualización de la vena hepática derecha, la cual se disecó (Figura 4C), para rodearla e instalar una sonda siliconada que permitió realizar la maniobra de suspensión del hígado (Figura 4D). Esta maniobra es útil para la preservación del plano de transección hepática. El siguiente paso fue la disección del pedículo hepático. Primero, se aisló la arteria hepática derecha (Figura 5A) y luego la vena porta derecha (Figura 5B). Se realizó una línea de transección sobre el parénquima mientras se mantuvo clampeado temporalmente el pedículo hepático derecho (Figura 5C).

La transección del parénquima fue realizada meticulosamente sobre la línea previamente demarcada adyacente a la VHM, utilizando dispositivo Harmonic ${ }^{\circledR}$ HD 1000i, coagulación bipolar y CUSA $^{\circledR}$ laparoscópico, este último para los sectores más profundos del parénquima hepático y disección de estructuras vasculares hepáticas de mayor calibre.

Las ramas afluentes a la VHM de los segmentos V y VIII (Figura 5D) fueron cuidadosamente identificadas y seccionadas con ligaduras largas de manera de ser identificadas en caso eventual de requerir reconstrucción en la cirugía de banco. Antes de realizar la disección del conducto hepático derecho, se realizó una prueba de fluorescencia con verde de indocianina, utilizando la torre de laparoscopía 4K (Figura 6A). El compuesto denominado verde de indocianina es un fármaco de contraste, cuya presentación es en frasco ampolla de $25 \mathrm{mg}$, los cuales se disuelven en suero fisiológico para obtener una concentración de $2,5 \mathrm{mg}$ por $\mathrm{ml}$. Al paciente se le administraron $3 \mathrm{ml}$ de esta solución vía endovenosa. Este producto se excreta por la vía biliar, y es necesario administrar el compuesto 30 a 40 min previo a su uso para cumplir el objetivo de demarcar la vía biliar.

Con esto fue posible visualizar la confluencia de los conductos biliares, evitando daño de estructuras contralaterales (Figura 6B). La buena visualización de las estructuras biliares permitió prescindir de la colangiografía intraoperatoria. Antes del clampeo y sección de los elementos del pedículo (Figura 6 C, D) y de la vena hepática derecha (Figura 7A), se realizó la incisión transversa suprapúbica por donde se introdujo una bolsa de $15 \mathrm{~mm}$ EndoCatch ${ }^{\mathrm{TM}}$, dejándola preparada para la extracción de la pieza a manera de disminuir los tiempos de isquemia caliente. Finalmente se realizó la extracción de la pieza
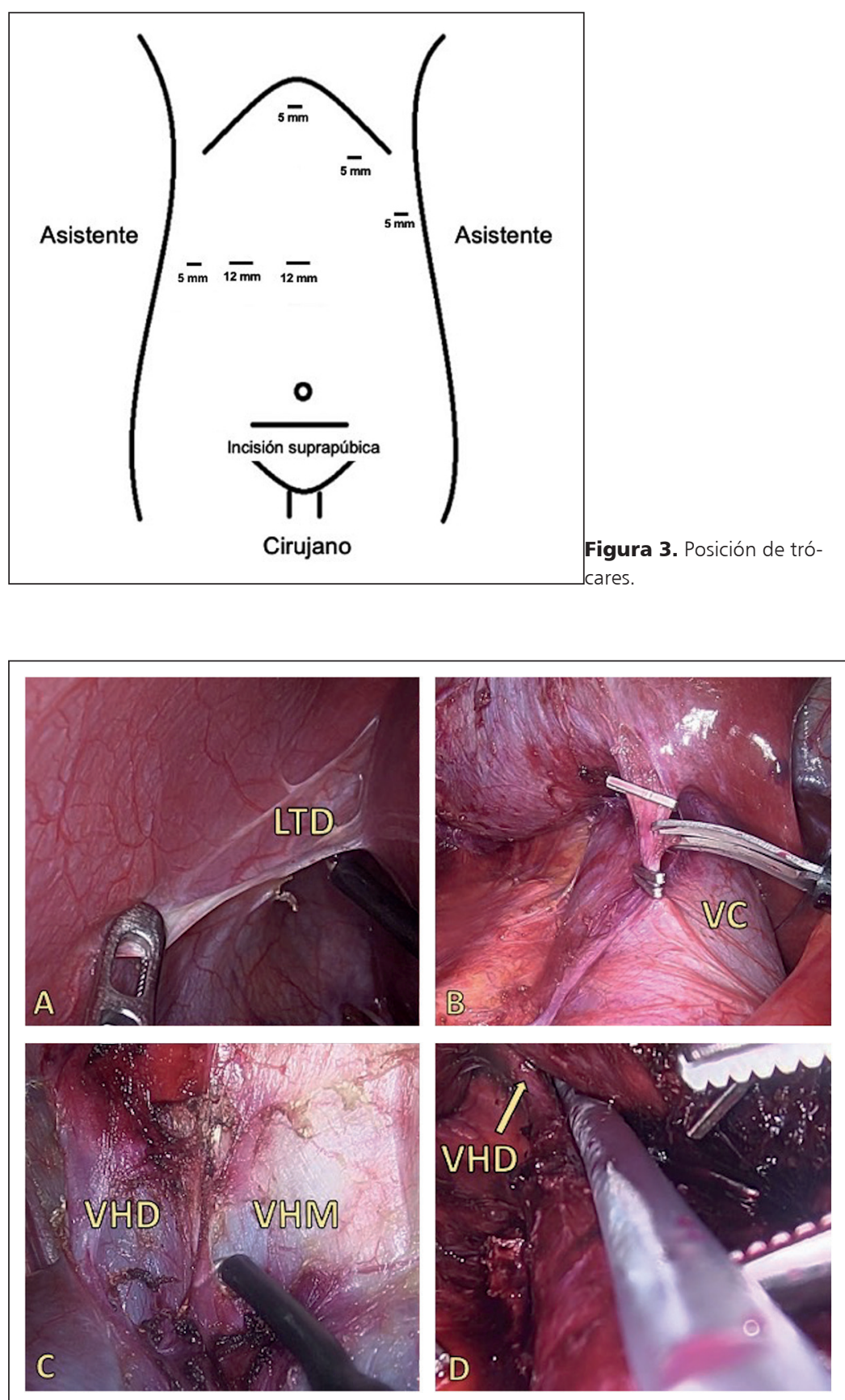

Figura 4. A: Liberación laparoscópica del lóbulo hepático derecho. LTD = ligamento triangular derecho. B: Liberación vena cava retrohepática. VC = vena cava. C: Disección vena hepática derecha. $\mathrm{VHD}=$ vena hepática derecha. $\mathrm{VHM}=$ vena hepática media. D: Instalación sonda para realizar maniobra de suspensión del hígado. VHD = vena hepática derecha 


\section{CIRUGíA AL DÍA}
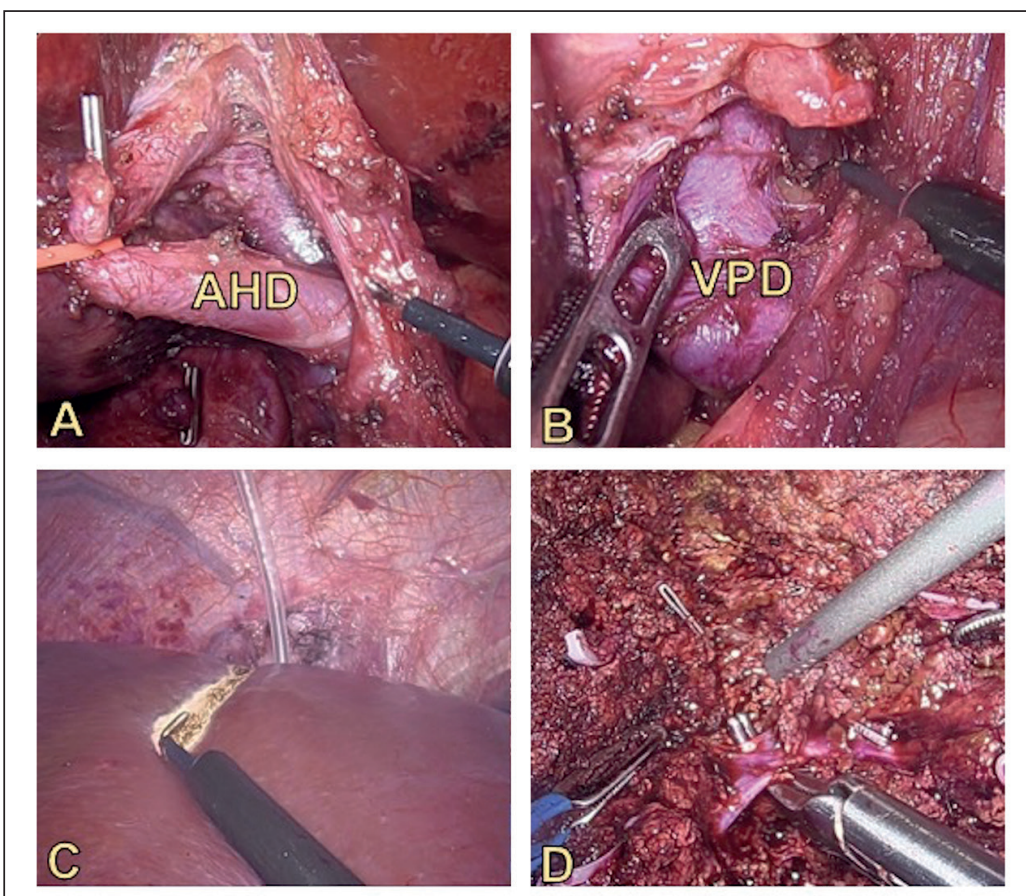

Figura 5. A: Se aísla y diseca arteria hepática derecha. AHD = arteria hepática derecha. B: Se aisla y diseca vena porta derecha. VPD = vena porta derecha. C: Se realiza línea de transección del parénquima mientras se mantiene clampeado transitoriamente el pedículo. D: Transección del parénquima hepático y control ramas V5 y V8 vena hepática media.
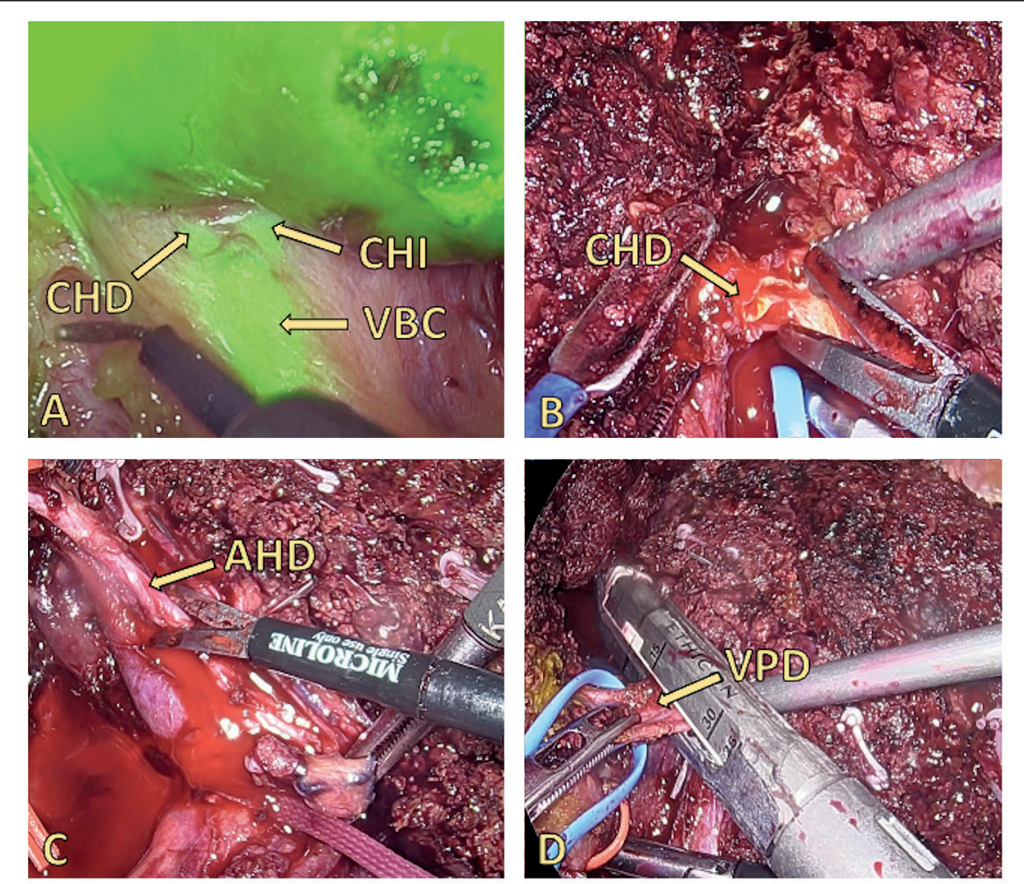

Figura 6. A: Prueba de fluorescencia con verde de indocianina. $\mathrm{VBC}=$ vía biliar común. $\mathrm{CHI}=$ conducto hepático izquierdo. B: Sección del conducto hepático derecho, evitando lesión del conducto hepático izquierdo. $\mathrm{CHD}=$ conducto biliar derecho. C: Sección AHD = arteria hepática derecha. D: Sección VPD = vena porta derecha. operatoria (Figura 7B) y se fijó el lóbulo hepático izquierdo remanente de manera de evitar su torsión posoperatoria (Figura 7C). Se dejó un drenaje aspirativo al lecho operatorio.

\section{Resultados}

El tiempo operatorio total fue de $360 \mathrm{~min}$. La estimación de sangrado intraoperatorio fue de $150 \mathrm{~mL}$. La maniobra de Pringle no fue necesaria, tampoco transfusiones de sangre ni hemoderivados. El peso del injerto fue de 928 gramos con una relación GW/ $\mathrm{RW}$ ratio $=1,45 \%$. El tiempo de isquemia caliente fue de $4 \mathrm{~min}$.

La donante inició ingesta oral al segundo día posoperatorio, se retiró el drenaje al tercer día, previa medición de bilirrubina del trayecto. Se dio de alta a la paciente al cuarto día sin incidentes ni complicaciones. La función del injerto alcanzó valores normales sin presentar complicaciones relacionadas. El paciente receptor presentó una colección subfrénica que fue drenada de forma percutánea sin incidentes. Además, presentó una fístula biliar de bajo débito que fue tratada de manera conservadora, difiriendo el retiro del drenaje, sin requerir tratamiento quirúrgico, endoscópico o percutáneo. El receptor fue dado de alta en buenas condiciones el día 20 posoperatorio.

\section{Discusión}

La técnica de HDTL para THDVA-A es un procedimiento complejo, cuyo principal objetivo es obtener la mejor calidad del injerto con la máxima seguridad para el donante, otorgándole, además, los beneficios de la cirugía mini-invasiva ${ }^{11}$. Por otro lado, en un país como Chile, donde la tasa de donación es persistentemente baja, nuestros resultados indican que el THDVA-A podría ser una alternativa segura y eficaz para los pacientes en lista de espera.

El THDV se inició en pacientes pediátricos, utilizando el segmento lateral izquierdo del hígado como injerto para el receptor. El éxito que alcanzó esta técnica en niños naturalmente provocó interés para su aplicación en adultos. Sin embargo, a pesar del inicial incremento que tuvo el THDVA-A en los años 90, las complicaciones asociadas e incluso el reporte de mortalidad de algunos donantes, produjo una franca disminución de estos procedimientos en países occidentales ${ }^{1,12}$. Sumado a lo anterior, las elevadas tasas de donación registradas cada año en Norteamérica y Europa, hacen que este procedi- 

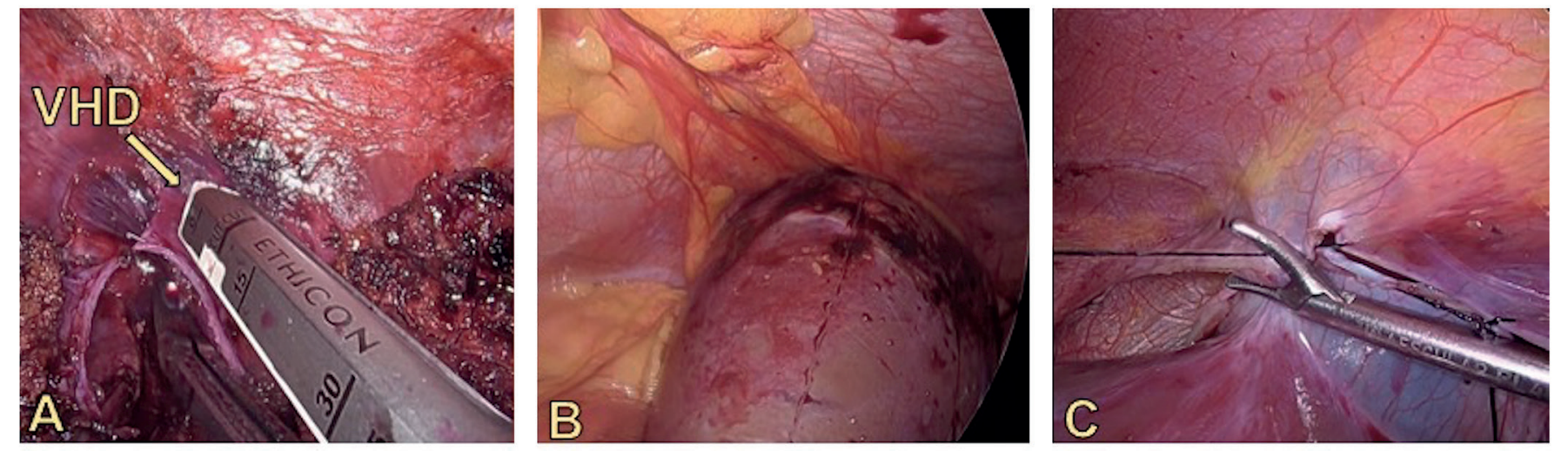

Figura 7. A: Sección VHD = vena hepática derecha, con stappler vascular. B: Extracción del injerto en una bolsa mediante incisión suprapúbica. C: Fijación de lóbulo hepático izquierdo a pared abdominal.

miento sea más bien de excepción, reservándose exclusivamente para pacientes con indicaciones no tradicionales de trasplante. Por el contrario, en regiones donde la tasa de donación cadavérica es muy baja, ha habido mayor interés por el desarrollo de THDV. Además, en países asiáticos como Japón, Korea y China, por razones culturares y religiosas el THDV es la técnica más utilizada, tanto en adultos como en niños ${ }^{13}$.

Por otro lado, en nuestro país, las tasas de donación no logran suplir la necesidad de trasplantes y como consecuencia, las listas de espera son prolongadas y la mortalidad muy elevada $(30-40 \%)^{14}$. Esto ha incentivado a algunos centros altamente especializados a desarrollar con éxito la técnica del THDV. Como se mencionó antes, principalmente para población pediátrica y en menor cuantía para población adulta.

Además de lo anterior, en los últimos años se ha desarrollado el trasplante hepático en el campo de la oncología. Han aumentado las indicaciones de trasplante hepático para pacientes con metástasis hepáticas y también para criterios extendidos de hepatocarcinoma ${ }^{15}$. Por lo tanto, el THDVA-A ha adquirido nuevamente relevancia en los tiempos actuales, y ha vuelto a despertar interés en países occidentales. Es importante mencionar que el gran volumen de THDV que realizan los países asiáticos, ha permitido mejorar y estandarizar la técnica, de manera de proteger la seguridad de los donantes, otorgando las ventajas que ofrece la cirugía miniinvasiva y, al mismo tiempo, procurar un buen injerto para los receptores ${ }^{4}$.

El primer reporte en la literatura de una HDTL para THDVA-A fue realizado en 2013 por Soubra- $n \mathrm{e}^{16}$, a partir de ese entonces y especialmente los últimos dos años, el desarrollo de esta técnica se ha incrementado y algunos centros han publicado exitosos resultados al respecto ${ }^{5}$. No obstante, la viabilidad y seguridad de este procedimiento aún está en desarrollo y no ha sido completamente evaluada, si bien las series de casos no son menores, el tiempo de seguimiento es relativamente corto y las publicaciones aún son escasas. Los trabajos de Hong $(2020)^{7}$, Jeong $(2020)^{8}$, Rhu (2019) $)^{9}$, Suh $(2018)^{10}$ y Lee $(2018)^{11}$, representan las 5 series de casos de mayor volumen sobre HDTL para THDVA-A. En todos estos estudios, la HDTL se asoció a menor sangrado, mejor evolución posoperatoria en relación con dolor, disminución de la tasa de complicaciones posoperatorias y estadía hospitalaria más corta comparada con la vía tradicional abierta.

Según nuestro conocimiento, el trabajo de Hong ${ }^{7}$, constituye la serie de casos de mayor volumen publicada hasta la fecha sobre HDTL versus técnica tradicional abierta para THDVA-A. Sus resultados, con 213 donantes sometidos a HDTL, describen ausencia de complicaciones irreversibles y mortalidad en este grupo. La segunda serie comparativa más relevante corresponde a la publicada por Jeong ${ }^{8}$, con 123 casos. Dentro de sus resultados destaca que el grupo operado por vía laparoscópica presentó menor tiempo de estadía hospitalaria y menor requerimiento de opiodes posoperatorios. Ambos estudios, describen una sobrevida del injerto y receptor similar entre el grupo de pacientes cuyos donantes fueron operados por vía tradicional abierta, versus en quienes se utilizó abordaje totalmente laparoscópico.

Respecto a la curva de aprendizaje, esta ha sido caracterizada como prolongada y compleja. Este 
aspecto constituye una de las principales razones por las cuales la técnica del THDVA-A no se ha generalizado globalmente. Lee ${ }^{11}$, describe la necesidad de al menos 60 casos de HDTL para THDVA-A para alcanzar la curva de aprendizaje necesaria y $\mathrm{Rhu}^{9}$, un total estimado de 50 casos. Además de la necesidad de contar con amplia experiencia previa, tanto en cirugía hepática laparoscópica como en THDV.

Por el momento, las series de casos publicadas en la literatura aún son escasas, y sólo unos pocos cirujanos en el mundo realizan este procedimiento. En este primer caso, el complemento de contar con un centro con experiencia en THDV, sumado a las habilidades laparoscópicas en cirugía hepatobiliar por parte del equipo quirúrgico, permitió realizar este procedimiento de manera mini-invasiva con seguridad, otorgando los ya conocidos beneficios de la laparoscopía al donante. Es fundamental también, contar con el equipamiento adecuado. El aporte de la tecnología con visión $4 \mathrm{~K}$ y la técnica de fluorescencia con verde de indocianina fueron aportes relevantes en este primer caso. Si bien no se pueden obtener conclusiones con un solo caso, dado los crecientes reportes publicados en la literatura y la experiencia local inicial con THDV, pareciera posible desarrollar HDTL para THDVA-A en forma segura en un medio como el nuestro, tomando todas las precauciones que han sido mencionadas en el artículo.

\section{Responsabilidades éticas}

Protección de personas y animales. Los autores declaran que para esta investigación no se han realizado experimentos en seres humanos ni en animales.

Confidencialidad de los datos. Los autores declaran que en este artículo no aparecen datos de pacientes.

El Comité de Ética de Clínica Las Condes dio autorización y constancia sobre la publicación de este trabajo.

Conflictos de interés: no hay.

\section{Bibliografía}

1. Dagher I, Gayet B, Tzanis D, Tranchart H, Fuks D, Soubrane O, et al. International experience for laparoscopic major liver resection. J Hepato-Biliary-Pancreat Sci. 2014;21(10):732-6. Available from: http:// doi.wiley.com/10.1002/jhbp.140

2. Buell JF, Cherqui D, Geller DA, O’Rourke N, Iannitti D, Dagher I, et al. The international position on laparoscopic liver surgery: The Louisville Statement, 2008. Ann Surg. 2009;250:825-30.

3. Wakabayashi G, Cherqui D, Geller DA, Buell JF, Kaneko H, Han HS, et al. Recommendations for laparoscopic liver resection: a report from the second international consensus conference held in Morioka. Ann Surg. 2015;261:619-29.

4. Soubrane O, de Rougemont O, Kim K-H, Samstein B, Mamode N, Boillot O, et al. Laparoscopic Living Donor Left Lateral Sectionectomy: A New Standard Practice for Donor Hepatectomy. Ann Surg. 2015;262:757-61; discussion 761-3.

5. Cho H-D, Samstein B, Chaundry S, Kim K-H. Minimally invasive donor hepatectomy, systemic review. Int J Surg Lond Engl. 2020;82:187-91.
Available from: https://doi.org/10.1016/j. ijsu.2020.06.023.

6. Troncoso A, Sanhueza M, Rodríguez J, Pattilo JC, Briceño E, Guerra JF, et al. Donante vivo hepático adultopediátrico totalmente laparoscópico. Aspectos técnicos y resultados. Rev. Cir. 2020;72:510-5. Available from: http://dx.doi.org/10.35687/s245245492020006632.

7. Hong SK, Tan MY, Worakitti L, Lee J-M, Cho J-H, Yi N-J, et al. Pure Laparoscopic Versus Open Right Hepatectomy in Live Liver Donors: A Propensity Score-matched Analysis. Ann Surg. 2020. Available from: 10.1097/ SLA.0000000000003914.

8. Jeong JS, Wi W, Chung YJ, Kim JM, Choi G-S, Kwon CHD, et al. Comparison of perioperative outcomes between pure laparoscopic surgery and open right hepatectomy in living donor hepatectomy: Propensity score matching analysis. Sci Rep. 2020;10:5314. Available from: http:// dx.doi.org/10.1038/s41598-020-62289-0.

9. Rhu J, Choi GS, Kim JM, Joh J-W, Kwon CHD. Feasibility of total laparoscopic living donor right hepatectomy compared with open surgery: comprehensive review of 100 cases of the initial stage. J HepatoBiliary-Pancreat Sci. 2020;27:16-25. Available from: http://dx.doi.org/10.1002/ jhbp.653.

10. Suh KS, Hong SK, Lee KW, Yi NJ, Kim HS, Ahn SW, et al. Pure laparoscopic living donor hepatectomy: Focus on 55 donors undergoing right hepatectomy. Am J Transplant Off J Am Soc Transplant Am Soc Transpl Surg. 2018;18:434-43.

11. Lee K-W, Hong SK, Suh K-S, Kim H-S, Ahn S-W, Yoon KC, et al. One Hundred Fifteen Cases of Pure Laparoscopic Living Donor Right Hepatectomy at a Single Center. Transplantation 2018;102:187884. Available from: http://dx.doi. org/10.1097/TP.0000000000002229.

12. Vilatobá M, Eckhoff D, Contreras J. Trasplante hepático de donador vivo adulto-adulto. Rev Invest Clin. 2005;57:252-61.

13. Chen C-L, Kabiling CS, Concejero AM. Why does living donor liver transplantation flourish in Asia? Nat Rev Gastroenterol Hepatol. 2013;10:746-51. Available from: http://dx.doi.org/10.1038/ nrgastro.2013.194.

14. Uribe M, González G, Alba A, Godoy J, Ferrario M, Hunter B, et al. Living 
CIRUgíA AL díA

donor liver transplantation in pediatric patients with acute liver failure: safe and effective alternative. Transplant Proc. 2008;40:3253-5. Available from: http://dx.doi.org/10.1016/j. transproceed.2003.09.02.
15. Giannis D, Sideris G, Kakos CD, Katsaros I, Ziogas IA. The role of liver transplantation for colorectal liver metastases: A systematic review and pooled analysis. Transplant Rev. 2020;34:100570. Available from: http:// dx.doi.org/10.1016/j.trre.2020.100570.

16. Soubrane O, Perdigao Cotta F, Scatton

O. Pure laparoscopic right hepatectomy in a living donor. Am $\mathrm{J}$ Transplant Off $\mathrm{J}$ Am Soc Transplant Am Soc Transpl Surg. 2013;13:2467-71. 